\title{
Enhanced laccase-mediated transformation of diclofenac and flufenamic acid in the presence of bisphenol $A$ and testing of an enzymatic membrane reactor
}

Veronika Hahn ${ }^{1,2^{*}}$, Mareike Meister ${ }^{1,2}$, Stephan Hussy ${ }^{3}$, Arno Cordes ${ }^{4}$, Günther Enderle ${ }^{3}$, Akuma Saningong ${ }^{5}$ and Frieder Schauer ${ }^{1}$

\begin{abstract}
The inadequate removal of pharmaceuticals and other micropollutants in municipal wastewater treatment plants, as evidenced by their detection of these substances in the aquatic environment has led to the need for sustainable remediation strategies. Laccases possess a number of advantages including a broad substrate spectrum. To identify promoting or inhibitory effects of reaction partners in the remediation processes we tested not only single compounds - as has been described in most studies — but also mixtures of pollutants. The reaction of diclofenac (DCF) and flufenamic acid (FA), mediated by Trametes versicolor laccase resulted in the formation of products, which were more hydrophilic than the respective reactant (reactant concentration of $0.1 \mathrm{mM}$; laccase activity $0.5 \mathrm{U} / \mathrm{ml}$ ). Analyses (HPLC, LC/MS) showed that the product $\mathbf{1} \mathbf{a}$ and $\mathbf{1} \mathbf{b}$ for DCF and FA, respectively, to be a para-benzoquinone imine derivative. The formation of $\mathbf{1}$ a was enhanced by the addition of bisphenol A (BPA). After 6 days $97 \%$ more product was formed in the mixture of DCF and BPA compared with DCF tested alone. Product $1 \mathbf{a}$ was also detected in experiments with micropollutant-supplemented secondary effluent. Within $24 \mathrm{~h} 67 \%$ and $100 \%$ of DCF and BPA were transformed, respectively $(25 \mathrm{U} / \mathrm{ml})$. Experiments with a membrane reactor (volume 10 l; phosphate buffer, pH 7) were in good agreement with the results of the laboratory scale experiments $(50 \mathrm{ml})$. $E C_{50}$-values were also determined. The data support the use of laccases for the removal or detoxification of recalcitrant pollutants. Thus, the enzyme laccase may be a component of an additional environmentally friendly process for the treatment stage of wastewater remediation.
\end{abstract}

Keywords: Quinone, Bioremediation, Detoxification, Pharmaceuticals, Biodegradation, Vibrio fischeri

\section{Introduction}

The daily use of anti-inflammatory drugs such as diclofenac (DCF) or flufenamic acid (FA) in creams or tablets, as well as of plastic materials which release bisphenol A (BPA), contributes to pollution with these environmentally dangerous compounds. BPA is used in plastic industries; consequently the release from different sources is conceivable such as packages for food

\footnotetext{
*Correspondence: veronikahahn@gmx.at

${ }^{1}$ Institute of Microbiology, Ernst-Moritz-Arndt-University Greifswald,

Friedrich-Ludwig-Jahn-Str. 15, 17487 Greifswald, Germany

Full list of author information is available at the end of the article
}

and drink, varnishes, paintings and glues (Barnabe et al. 2009). The main entries for pharmaceuticals such as DCF or FA in ground and surface water are sludge or effluents of wastewater treatment plants (WWTP) where the pollutants are insufficiently degraded. Another source is dung and manure of farm animals which were treated with these substances (Ternes 1998; Deblonde et al. 2011; Samaras et al. 2013; Carmona et al. 2014).

Only $17-69 \%$ of DCF is removed in sewage treatment plants (Ternes 1998; Zwiener et al. 2000; Heberer 2002a; Heberer and Feldmann 2005; Deblonde et al. 2011; Samaras et al. 2013). FA is also insufficiently removed in 
WWTP. Moreover, Gracia-Lor et al. (2012) and Carmona et al. (2014) described for DCF and FA higher concentrations in the effluent than in the corresponding influent of spanish WWTP. The authors proposed a release as result of a cleavage of transformation products, deconjugation of metabolites and desorption from organic material.

DCF, FA and BPA were found repeatedly in surface water. Ternes (1998) reported for DCF a median of $0.15 \mu \mathrm{g} / \mathrm{l}$ and a maximum of $1.20 \mu \mathrm{g} / \mathrm{l}$ for German river and stream water. In Berlin, up to $0.5-1 \mu \mathrm{g} / \mathrm{l}$ and $0.38 \mu \mathrm{g} / \mathrm{l}$ were found in the Teltowkanal and in ground water, respectively (Heberer 2002b). FA was detected in river and tap water with average concentrations of 21 and $16 \mathrm{ng} / \mathrm{l}$, respectively (Carmona et al. 2014). BPA was also found in surface and ground water (Loos et al. 2009, 2010). In small streams of the German region called Hessisches Ried BPA concentrations of up to $1.92 \mu \mathrm{g} / \mathrm{l}$ were detected (Quednow and Püttmann 2008).

DCF, FA as well as BPA may cause toxic effects. In rainbow trout DCF accumulates in the bile to a factor of approximately 580, and additionally the tested environmentally relevant concentrations caused necrosis in the kidney (Mehinto et al. 2010). The endocrine disrupting compound BPA leads to the induction of feminization in aquatic organisms, such as frogs (Levy et al. 2004; Bhandari et al. 2015). Because of the potential risk for human health, DCF was included in a watch list of emerging pollutants by the EU (Commission 2013, 2015). Nadanaciva et al. (2013) working with zebrafish, showed a high toxicity for FA, but it was not possible to locate the morphological changes because the difference between the FA concentration with no effect where no death occur (NOEC) and the concentration causing $100 \%$ lethality $\left(\mathrm{LC}_{100}\right)$ was too small. Thus, for FA as well as DCF the same NOEC of $10 \mu \mathrm{M}$ was determined whereas the $\mathrm{LC}_{100}$ was $30 \mu \mathrm{M}$ for FA and $300 \mu \mathrm{M}$ for DCF, allowing the determination of morphological changes, such as liver browning, only for DCF (Nadanaciva et al. 2013). Furthermore, in vitro test showed a considerable effect of FA on liver mitochondria (Nadanaciva et al. 2013).

The repeated detection of pharmaceutical residues in the aquatic environment demonstrates the urgent need for efficient wastewater treatment processes. In this regard, the enzyme laccase has been considered as a tool for a sustainable remediation strategy and for additional purification steps in wastewater treatment. Laccases [E.C. 1.10.3.2] can oxidize a broad range of compounds such as phenols or amines (Keilin and Mann 1939; Bollag et al. 1988; Thurston 1994; Mikolasch and Schauer 2009) by one-electron-reactions (Nakamura 1960; Solomon et al. 2001, 2008; Munk et al. 2017). In these laccase-mediated oxidations, radicals are formed which can undergo two possible reactions. The first involves binding to other compounds, while the second involves cleavage (Hahn et al. 2014). An important advantage of laccases, in particular for remediation purposes, is their need for atmospheric oxygen as the only co-substrate. Thus, oxygen is reduced to water.

Despite the well known removal of water contaminants such as BPA or other phenols, DCF and estrogens by free or immobilized laccase of Trametes versicolor (Auriol et al. 2008; Catapane et al. 2013; Ammann et al. 2014) has until now in most studies been tested only single compounds. The transformation in mixtures of micropollutants was described in most cases without the distinction of the influencing effect of the single compounds on the degradation in these mixtures (Tran et al. 2010; Nguyen et al. 2014; Asif et al. 2017b). To determine the effect of multiple contaminants on transformation rate and product formation we employed mixtures of pollutants. In addition, removal of FA was tested due to limited data.

The laccase of T. versicolor was employed for the transformation of DCF, FA and BPA and combinations of the substances were also tested. The removal of these test substances as well as product formation was determined by HPLC analyses. The structural characterization of products was performed by LC/MS.

The results of this study will be used for the development of an enzyme-based membrane reactor designated as an additional or tertiary treatment stage in sewage treatment plants.

\section{Materials and methods \\ Chemicals}

All chemicals used were of analytical grade and were used as received.

Diclofenac sodium salt, flufenamic acid, bisphenol A, 4'-hydroxydiclofenac and ABTS (2,2'-azino-bis(3-ethylbenzothiazoline-6-sulfonic acid) diammonium salt) were purchased from Sigma-Aldrich Chemie $\mathrm{GmbH}$ (Steinheim, Germany). 5-Hydroxydiclofenac was obtained from Toronto Research Chemicals (Toronto, Canada). Potassium dihydrogen phosphate and di-sodium hydrogen phosphate dihydrate were purchased from Carl-Roth GmbH and Co. KG (Karlsruhe, Germany).

\section{Enzyme}

The laccase from $T$. versicolor was obtained from ASA Spezialenzyme GmbH (Wolfenbüttel, Germany). The company markets the enzyme under the name "laccase C". It was produced by a fed-batch fermentation process. The fungal biomass was separated by centrifugation and the enzyme-containing supernatant was concentrated by ultrafiltration. After addition of stabilizing agents the retentate of the ultrafiltration step was lyophilized. The laccase is active within $\mathrm{pH} 3.0-7.5(\mathrm{pH}$ 
optimum of 5). It was used as received (activity $>800$ $\mathrm{U} / \mathrm{g}$; substrate:syringaldazine).

For transformation experiments the laccase was used in Sørensen's phosphate buffer at $\mathrm{pH} 7$ in accordance with the $\mathrm{pH} 7-7.5$ of the secondary wastewater.

\section{Experimental procedures for transformation in phosphate buffer or secondary effluent}

For the transformation assays the respective compounds (initial reactant concentration: $0.1 \mathrm{mM}$ ) were incubated in a final volume of $50 \mathrm{ml}$ in $500-\mathrm{ml}$ flasks. The reaction solution was phosphate buffer or secondary effluent. The laccase activity was $0.5 \mathrm{U} / \mathrm{ml}$ for reactions in phosphate buffer and, additionally, 2.5 and $25 \mathrm{U} / \mathrm{ml}$ in wastewater. The secondary effluent from a wastewater treatment plant (85,000 inhabitant equivalents Greifswald, Germany) was $0.22 \mu \mathrm{m}$ filtered and spiked with the respective compound.

In controls the respective compounds were incubated in phosphate buffer or secondary effluent without laccase. Reaction mixtures were incubated with agitation at $150 \mathrm{rpm}$ at $25^{\circ} \mathrm{C}$ in the dark.

\section{Reactor setup and operation}

The laboratory reactor was equipped with an Atec ultrafiltration system to avoid loss of laccase (Fig. 1). From the different membranes tested for that purpose a tubular ceramic membrane element with a pore size of $10 \mathrm{~nm}$ gave the best results (Membrane: gamma- $\mathrm{Al}_{2} \mathrm{O}_{3}$, support: alpha $\mathrm{Al}_{2} \mathrm{O}_{3}$, manufacturer:Inopor). Like Atec's commercial Miditube filtration systems the laboratory unit uses a unique design allowing almost independent control of cross flow over the membrane surface, and trans membrane pressure. Filtration with low trans membrane pressures leads only to the formation of thin layers on the ultrafiltration membranes extending the time interval to back flush.

Depending on the temperature $\left(20-27{ }^{\circ} \mathrm{C}\right)$ the permeate flow of $26-36 \mathrm{l} /\left(\mathrm{m}^{2} \mathrm{~h}\right.$ bar) was constant during experiment if working pressure was kept low (1.1 bar). The ratio of bleeding to permeate flow was adjusted to 15:1. System was run continuously during duration of the experiment $(4 \mathrm{~h})$.

The respective substances (initial reactant concentration: $0.1 \mathrm{mM}$ ) were tested in a final volume of $10 \mathrm{l}$ in phosphate buffer. The laccase activity employed was 0.5 $\mathrm{U} / \mathrm{ml}$.

The decrease of reactants and the products formed were analyzed by HPLC.

\section{Measurement of laccase activity}

The activity of laccase was determined spectrophotometrically at $420 \mathrm{~nm}$ with ABTS as substrate (Bourbonnais and Paice 1990) using the method described by Jonas

\section{permeate}

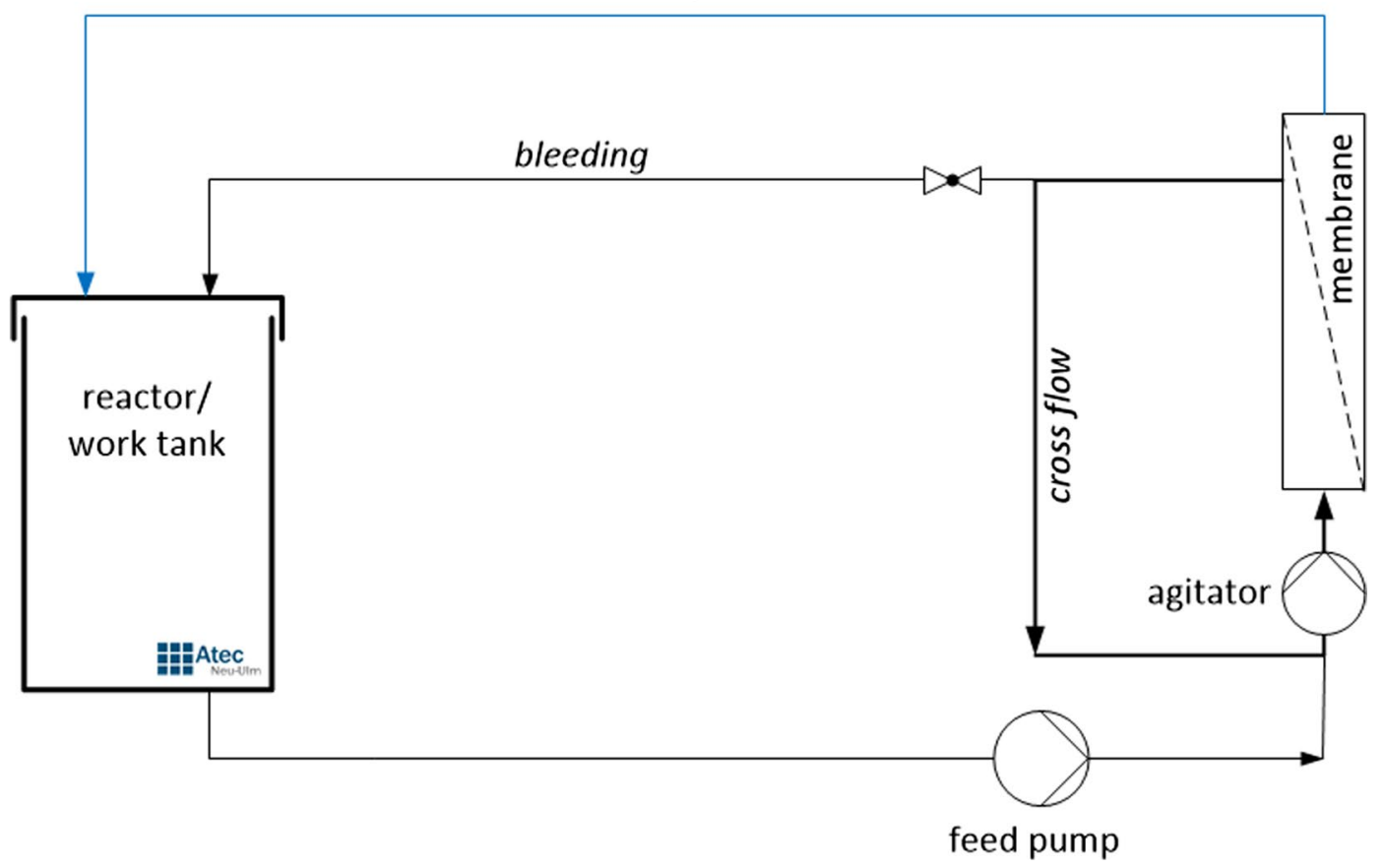

Fig. 1 Scheme of the reactor equipped with an Atec ultrafiltration system 
et al. (1997) at pH 5. $1 \mathrm{U}$ is defined as the turnover of $1 \mu \mathrm{mol} / \mathrm{ml} \mathrm{min}$

\section{Analytical HPLC (high-pressure liquid chromatography)} For routine analysis, the reaction mixtures were analyzed using an HPLC system LC-10AT VP (Shimadzu, Germany) consisting of a FCV-10AL VP pump, SPD-M10A VP diode array detector, and a SCL-10A VP control unit controlled by Class-VP version 6.12 SP5. Substances were separated on an endcapped, $5-\mu \mathrm{m}, \mathrm{LiChroCART}^{\circledR} 125-4$ RP18 column (Merck, Darmstadt, Germany) run at a flow rate of $1 \mathrm{ml} / \mathrm{min}$. The solvent system used consisted of a gradient of methanol (eluent $\mathrm{A}$ ) and $0.1 \%$ phosphoric acid (eluent B), starting from an initial ratio of $10 \% \mathrm{~A}$ and $90 \% \mathrm{~B}$ and reaching $100 \%$ methanol within $14 \mathrm{~min}$. Elution with methanol was continued for a further $6 \mathrm{~min}$.

\section{Structural characterization of products by LC/MS (liquid chromatography/mass spectrometry)}

The reaction mixtures and isolated products were characterized using a LC/MS system. The atmospheric pressure ionization (API) mass spectrometry experiments were performed on an Agilent Series 1200 HPLC system with diode array detector and an Agilent 6120 quadrupole mass spectrometer (Waldbronn, Germany). The MS was run with the electrospray ionization (API-ES) source in positive mode (dry and nebulizer gas: nitrogen; nebulizer pressure: 45 psig; drying gas flow: $10 \mathrm{l} / \mathrm{min}$; drying gas temperature: $350{ }^{\circ} \mathrm{C}$; capillary voltage: $4 \mathrm{kV}$; fragmentor voltage: $75 \mathrm{~V})$. HPLC separation was performed on a Zorbrax SB-C18 $(2.1 \times 50 \mathrm{~mm}, 1.8 \mu \mathrm{m})$ column (Agilent, Waldbronn, Germany), at a flow rate of $0.07 \mathrm{ml} / \mathrm{min}$. The solvent system consisted of a gradient of acetonitrile (eluent $\mathrm{A}$ ) and $0.1 \%$ aqueous ammonium formate (eluent
B), starting from an initial ratio of 10\% A and 90\% B and reaching $100 \%$ methanol within $7 \mathrm{~min}$. Elution with methanol was continued for a further 6 min.

Experimental methods; UV-vis data and MS spectra for products $\mathbf{1} \mathbf{a}_{\mathrm{I}-\mathrm{III}}, \mathbf{2}$, and $\mathbf{1 b}_{\mathrm{I}, \mathrm{II}}$ (Additional file $\mathbf{1}$ : Table S1-S6) are available in the electronic additional file.

\section{Determination of toxicity using Vibrio fischeri (DIN EN ISO 11348, (DIN 38412-L34, DIN 38412-L341))}

This marine bacterium is bioluminescent and emits light with a wavelength of $490 \mathrm{~nm}$. The bioluminescence is reduced in the presence of toxic agents.

Samples were taken before and after laccase treatment from a membrane reactor (initial concentration of reactants: $0.1 \mathrm{mM}$, volume: $10 \mathrm{l}$; phosphate buffer; incubation time: $4 \mathrm{~h}$ ).

For the determination of $\mathrm{EC}_{20}$ and $\mathrm{EC}_{50}$ the samples were inoculated with Vibrio fischeri (LCK 482, Hach Lange GmbH, Düsseldorf, Germany) and incubated for $30 \mathrm{~min}$. The reduction of bioluminescence was measured photometrically (LUMIStox 300-Version 3.03 Hach Lange $\mathrm{GmbH}$, Düsseldorf, Germany). The results were compared with a control containing physiological saline solution instead of the sample.

\section{Results}

Transformation of DCF, FA and BPA including structural characterization of the products formed

DCF, FA and BPA were transformed by laccase of $T$. versicolor to varying extents (concentration of reactants: $0.1 \mathrm{mM}$; Fig. 2). The reactant BPA was completely transformed within $24 \mathrm{~h}$ in the laccase-mediated reactions irrespective of whether it was tested individually or in combination with DCF or FA. The influence of added
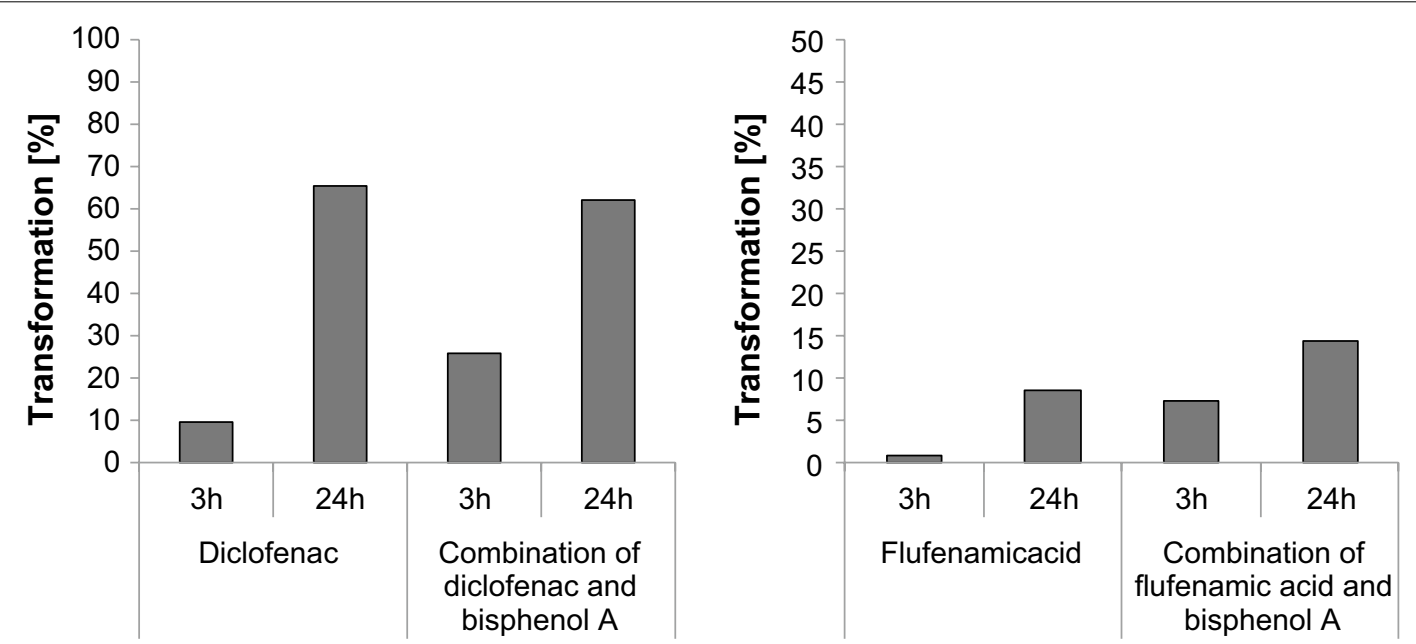

Fig. 2 Laccase-mediated transformation [\%] of DCF or FA treated individually or in combination with BPA in phosphate buffer (concentration of reactants $0.1 \mathrm{mM}$ ) 
BPA on the transformation of the other two compounds was significant within $3 \mathrm{~h}$. In the reaction with BPA the acids DCF and FA were 2.7 and 7 times faster transformed in the presence of BPA. After $24 \mathrm{~h}$ DCF transformation reached approximately $65 \%$ in both reactions whereas FA reached 9\% (without BPA) and 15\% (with BPA).

For all reactions different low- and high-molecular weight products were detected but due to the small quantities and difficult analyses (at least for the highmolecular weight products) only a selection of products were structurally characterized.

The laccase-mediated reaction of DCF leads to the formation of product $\mathbf{1} \mathbf{a}_{\mathbf{I}}$ which was detected after an incubation period of 6 days. In combination of DCF and BPA the product $\left(\mathbf{1} \mathbf{a}_{\mathrm{II}}\right)$ was detected already after $3 \mathrm{~h}$. Thus, within 6 days only $3 \%$ of $1 \mathbf{a}_{\mathbf{I}}$ was formed in the reaction of DCF $\left(1 \mathbf{a}_{\mathrm{I}}: 0.39 \mu \mathrm{g} / \mathrm{ml} ; 0.0013 \mathrm{mM}\right)$ compared to the mixture of DCF and BPA (1 $\left.\mathbf{a}_{\mathrm{II}}: 13.34 \mu \mathrm{g} / \mathrm{ml} ; 0.0430 \mathrm{mM}\right)$.

The product $1 \mathbf{a}_{\mathrm{I}}$ was more hydrophilic $\left(\mathrm{R}_{\mathrm{f}} 12.23 \mathrm{~min}\right)$ than DCF ( $\left.R_{\mathrm{f}} 14.18 \mathrm{~min}\right)$ and showed UV-vis absorption maxima at 202, 267 and $462 \mathrm{~nm}$ (Table 1). The LC/ MS (API-ES positive mode) analyses of $1 \mathbf{a}_{\mathbf{I}}$ resulted in the detection of $[\mathrm{M}+\mathrm{H}]^{+}$ion multiplets at $m / z$ (rel. intensity) 310.0, 312.0 and 313.8 (90:74:5; Additional file 1: Table S1) implying an hydroxylation and oxidation of DCF.

The UV-vis absorption maximum at $267 \mathrm{~nm}$ as well as the ion multiplets at $m / z$ 310.0, 312.0 and 314.0 (Additional file 1: Table S3) were reported by Shen et al. (1999) for the $p$-benzoquinone imine derivative $\left(\mathbf{1} \mathbf{a}_{\text {III }}\right)$ of 5-hydroxydiclofenac (5HDCF) formed during incubation of DCF with liver microsomes. Thus, the reactions of DCF (alone or in a mixture with BPA) or 5HDCF resulted in the same product 1a. For the laccase-mediated DCF transformation a hydroxylation at C5 with subsequent formation of a $p$-benzoquinone imine $\mathbf{1 a}_{\mathbf{I}, \mathbf{I I}}$ was presumed.

The $4^{\prime}$-hydroxydiclofenac ( $\left.4^{\prime} \mathrm{HDCF}\right)$ was incubated with laccase to exclude the $4^{\prime}$-position for the hydroxylation. The reaction resulted in the formation of the corresponding quinone imine (2). The LC/MS (API-ES positive mode) analyses of 2 resulted also in the detection of $[\mathrm{M}+\mathrm{H}]^{+}$ion multiplets at $\mathrm{m} / z$ (rel. intensity) 310.0, 312.0, 314.0 (100, 62, 18; Table 1; Additional file 1: Table S4) but the retention time of $12.41 \mathrm{~min}$ as well as the UV-vis absorption maxima at 202, 278, $524 \mathrm{~nm}$ were different to those of $\mathbf{1} \mathbf{a}_{\text {I-III }}$.

Table 1 Structural data of products $1 \mathrm{a}_{1-\text { III }}$ formed during laccase-mediated reactions of DCF alone or in combination with BPA as well as 5HDCF; data for product 2 from the reaction of $4^{\prime}$ HDCF and for products $1 b_{1,11}$ from the reaction of FA alone or in combination with BPA are provided

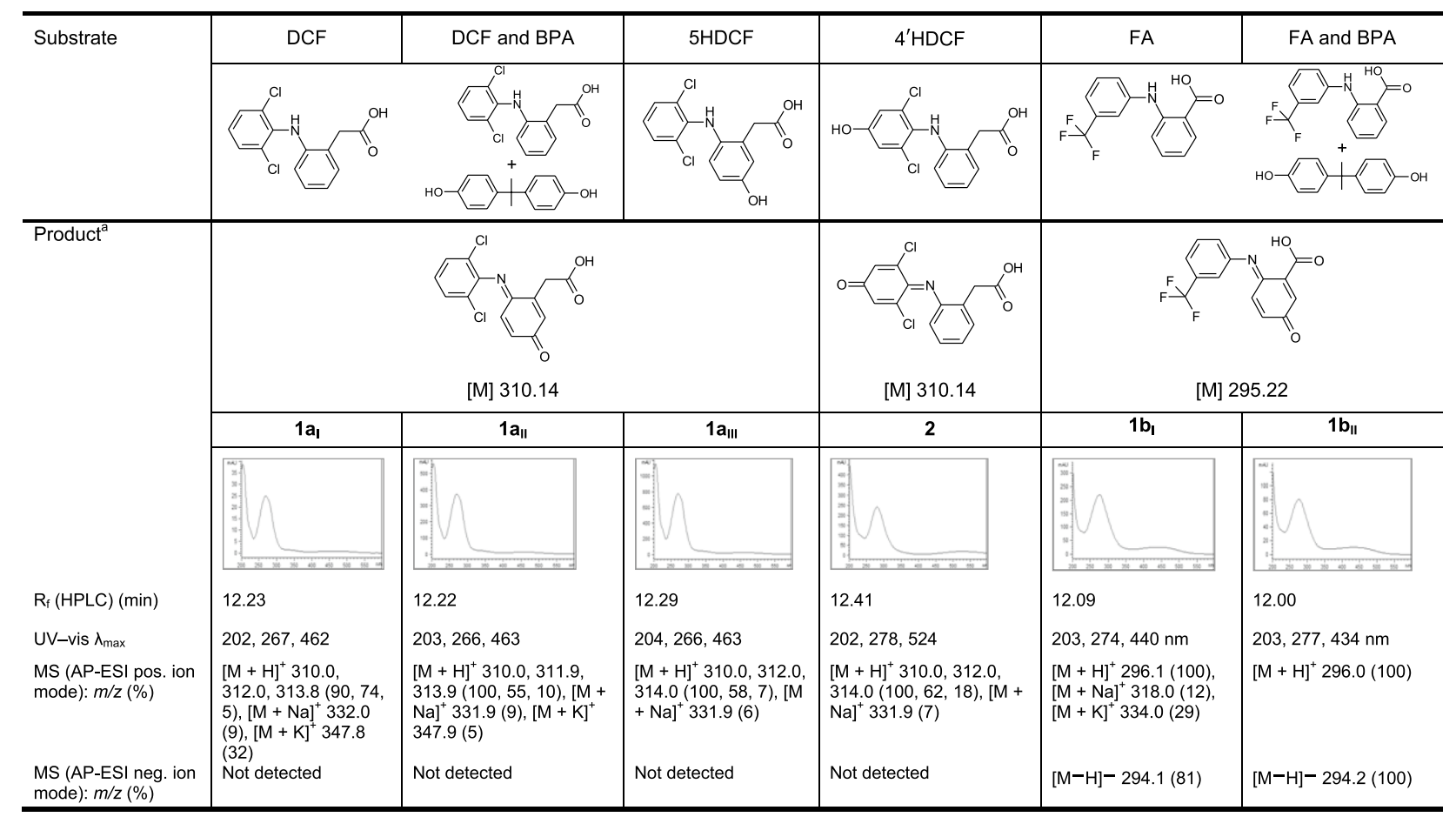

According to the HPLC and LC/MS data products $\mathbf{1} \mathbf{a}_{1-1 I I}$ and $\mathbf{1} \mathbf{b}_{1, \mathrm{II}}$ have the same chemical structure, respectively

a Only Products of DCF and FA are shown 
Similar to the reaction of DCF the reaction of FA alone and in combination with BPA resulted after 10 days in a more hydrophilic product $\left(\mathbf{1 b}_{\mathbf{I}} \mathbf{R}_{\mathrm{f}} \mathbf{1 2 . 0 9} \mathrm{min}\right.$ or $\mathbf{1 b}_{\mathrm{II}} \mathbf{R}_{\mathrm{f}}$ $12.00 \mathrm{~min})$ than FA ( $\left.\mathrm{R}_{\mathrm{f}} 14.99 \mathrm{~min}\right)$. The LC/MS analyses (API-ES positive and negative mode) for the laccasemediated reaction of FA resulted in the detection of $[\mathrm{M}+\mathrm{H}]^{+}$(rel. intensity) 296.1 (100), $[\mathrm{M}+\mathrm{Na}]^{+}$318.0, $[\mathrm{M}+\mathrm{K}]^{+} 334.0$ and $[\mathrm{M}-\mathrm{H}]^{-} 294.1$ (Additional file 1: Table S5). The C4-position for the hydroxylation was assumed because of the similarities with the reaction of DCF, though no authentic standard was available. The amount of products $\left(\mathbf{1}_{\mathrm{I}, \mathrm{II}}\right)$ formed was too small to determine a dependency between product yield and BPA addition. The concentration of BPA may not have been high enough to promote the formation of $\mathbf{1} \mathbf{b}_{\mathrm{II}}$.

\section{DCF transformation alone and in combination with BPA in a membrane reactor and determination of toxicity}

Experiments with a membrane reactor (volume of $10 \mathrm{l}$ ) were carried out to provide information about the efficiency of laccase-mediated transformation of pollutants.

In samples of laboratory scale, and in the filtrate of a membrane reactor, DCF transformation was enhanced by the presence of BPA (Fig. 3). Thus, in both situations the removal of DCF was approximately $20 \%$ higher after $4 \mathrm{~h}$ in the mixture of DCF and BPA than without BPA. Furthermore, 1 $\mathbf{a}_{\text {I }}$ was not detected when DCF was tested alone due to the short incubation time of $4 \mathrm{~h}$. In the combination of DCF and BPA the product $1 \mathbf{a}_{\mathrm{II}}$ was formed as in the $50 \mathrm{ml}$ assay. The loss of laccase during the $4 \mathrm{~h}$ incubation in the reactor was negligible.

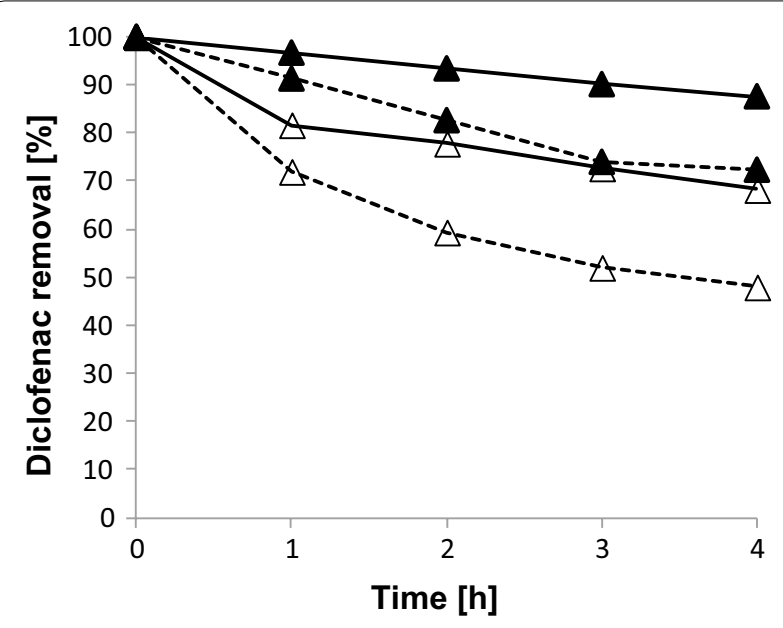

Fig. 3 Transformation of DCF tested individually (black lines) and in mixture with BPA (dashed lines) in 500-ml flasks (laboratory scale; reaction volume: $50 \mathrm{ml}$; filled triangles) and in filtrate of a membrane reactor (reaction volume: $10 \mathrm{l}$; open triangle) in phosphate buffer $(\mathrm{pH} 7)$ and a laccase activity of $0.5 \mathrm{U} / \mathrm{ml}$ (concentration of reactants: $0.1 \mathrm{mM})$
The reaction assays of the membrane reactor were tested for their toxicity against Vibrio fischeri before and after incubation with laccase (Table 2). In all tested assays the toxicity decreased with decreasing concentration of the pollutant/s caused by laccase-mediated transformation. After an incubation time of $4 \mathrm{~h} 32 \%$ of DCF was removed whereas in the mixture with BPA $52 \%$ of DCF was transformed. The reactions with BPA resulted in a complete transformation.

For DCF and BPA the toxicity was reduced by 42 and $76 \%$, respectively (according to $\mathrm{EC}_{50}$-values). In the reaction of DCF with BPA the toxicity was diminished by $69 \%$ after laccase treatment. The residual toxicity is probably caused by products formed or-in case of DCF-by the high concentration of reactant, which is left in the reaction assay. Nevertheless, the data show a clear decrease in toxicity due to laccase treatment. A longer incubation time would be expected to lead to higher transformation of DCF, which may cause a further decrease in toxicity.

\section{DCF transformation alone and in combination with BPA in municipal wastewater}

A laccase activity of 0.5 or $2.5 \mathrm{U} / \mathrm{ml}$ was used for the experiments with the secondary effluent. However, this activity, as seen in the previous experiments, resulted in no transformation of DCF. $25 \mathrm{U} / \mathrm{ml}$ in wastewater was needed to achieve $67 \%$ transformation of DCF and complete removal of BPA within $24 \mathrm{~h}$. In the mixture of DCF and BPA $33 \%$ and $65 \%$ were transformed, respectively.

Within $24 \mathrm{~h} \mathbf{1} \mathbf{a}_{\mathbf{I}}$ was only detected in the reaction with DCF alone $\left(\mathbf{1} \mathbf{a}_{\mathbf{I}} 7.03 \mu \mathrm{g} / \mathrm{ml} ; 0.0227 \mathrm{mM}\right)$ in accordance with the faster transformation of DCF in this reaction compared to the reaction in a mixture with BPA.

\section{Discussion}

Laccase-mediated reactions resulted in the transformation of micropollutants which are problematic for aquatic environment. The transformation efficiency of BPA, DCF, and FA mediated by $T$. versicolor laccase in the lab scale reactions (reaction volume $50 \mathrm{ml}$; phosphate buffer) was: BPA > DCF > FA. The laccase-mediated oxidation can be hindered by different factors such as steric problems through the size of the substrate-binding site (Tadesse et al. 2008; Galli et al. 2011).

Moreover, it is believed that laccase can only oxidize those substrates which have a redox potential below that of the enzyme (Xu et al. 2000). Thus, laccases were divided according to their redox potential into low (0.4$0.5 \mathrm{~V}$, determined against a normal hydrogen electrode) and high redox potential (0.7-0.8 V) laccases (Xu 1996; $\mathrm{Xu}$ et al. 1998; Li et al. 1999; Frasconi et al. 2010). The laccase of $T$. versicolor belongs to the high redox potential laccases (0.785 V, Reinhammar 1972). The low redox 
Table 2 Results of the toxicity test (test organism: Vibrio fischeri), including concentration of DCF and BPA, before and after laccase treatment in a membrane reactor (volume: $10 \mathrm{l}$; phosphate buffer; incubation time: $4 \mathrm{~h}$ )

\begin{tabular}{|c|c|c|c|c|c|c|c|c|}
\hline \multirow[t]{3}{*}{ Reaction } & \multicolumn{4}{|c|}{ Concentration } & \multicolumn{4}{|c|}{ Toxicity test (Vibrio fischeri) } \\
\hline & \multicolumn{2}{|l|}{ DCF } & \multicolumn{2}{|l|}{ BPA } & \multicolumn{2}{|l|}{$\mathrm{EC}_{50}$} & \multicolumn{2}{|l|}{$\mathrm{EC}_{20}$} \\
\hline & $\mathrm{mg} / \mathrm{l}$ & $\mathrm{mM}$ & $\mathrm{mg} / \mathrm{l}$ & $\mathrm{mM}$ & $\mathrm{mg} / \mathrm{l}$ & $\mathrm{mM}$ & $\mathrm{mg} / \mathrm{l}$ & $\mathrm{mM}$ \\
\hline \multicolumn{9}{|l|}{ DCF } \\
\hline Before laccase treatment & 31.81 & 0.10 & & & 11.36 & 0.0357 & 5.53 & 0.0174 \\
\hline After laccase treatment & 21.70 & 0.07 & & & 19.50 & 0.0613 & 9.59 & 0.0302 \\
\hline \multicolumn{9}{|l|}{ BPA } \\
\hline Before laccase treatment & & & 22.83 & 0.10 & 5.24 & 0.0230 & 1.36 & 0.0060 \\
\hline After laccase treatment & & & 0 & 0 & 22.16 & 0.0971 & 3.01 & 0.0132 \\
\hline \multicolumn{9}{|l|}{ DCF and BPA } \\
\hline Before laccase treatment & 31.81 & 0.10 & 22.83 & 0.10 & 3.91 & 0.0143 & 1.50 & 0.0055 \\
\hline After laccase treatment & 15.27 & 0.05 & 0 & 0 & 12.41 & 0.0454 & 6.24 & 0.0225 \\
\hline
\end{tabular}

potential of mono- and dihydroxylated aromatic compounds such as guaiacol or hydroquinone $(0.5-0.6 \mathrm{~V})$ allows an easy oxidation by laccase (Mai et al. 2001). The kind of substituents has also an influence on the oxidizability (Tadesse et al. 2008; Hahn et al. 2014). Thus, electron-withdrawing groups such as fluoro or chloro and carboxyl groups which are part of DCF and FA reduce the possibility for oxidation whereas electron-donating hydroxyl groups of BPA decrease the redox potential resulting in an easier oxidation.

The addition of BPA at least slightly enhanced the transformation of DCF and FA although complete transformation was not achieved. An incomplete biotransformation of DCF by laccase is not unexpected, and was also described for another laccase preparation of $T$. versicolor (Sigma-Aldrich Chemie GmbH, ref. 38429, Buchs, Switzerland) by Margot et al. (2013).

The reaction of DCF and BPA in 101 phosphate buffer in the membrane reactor resulted also in enhanced transformation of DCF in the presence of BPA. This demonstrates that the scale up was successful. In both-the $50 \mathrm{ml}$ and $10 \mathrm{l}$ scale-experiments the removal of DCF was approximately $20 \%$ higher after $4 \mathrm{~h}$ in the mixture of DCF and BPA than without BPA.

Nair et al. (2013) described an efficient transformation of DCF by immobilized laccase of Coriolopsis gallica in a continuous stirred tank membrane reactor, though the reactor volume was only $50 \mathrm{ml}$ (flow rate: $40 \mathrm{ml} / \mathrm{h}$ ). Thus, $70 \%$ of the DCF was transformed within $80 \mathrm{~h}$ (initial concentration: $10 \mu \mathrm{M}$, laccase activity approximately $1 \mathrm{U} / \mathrm{ml}$, McIlvaine buffer pH5). Nguyen et al. (2014) described the removal of BPA and DCF in an enzymatic membrane reactor using the laccase of Myceliophthora thermophila. Within $132 \mathrm{~h} 85 \% \mathrm{BPA}$ and 60\% DCF was continuously transformed (initial concentration $500 \mu \mathrm{g} / \mathrm{l} \mathrm{d}$, laccase activity approximately $90 \mu \mathrm{M} / \mathrm{min}$, Milli-Q-water). A further experiment with the same laccase and a mixture of BPA, DCF with 28 other pharmaceutics such as naproxen or ibuprofen was described by Asif et al. (2017b). In the enzymatic reactor approximately $88 \%$ BPA and 45\% DCF were transformed (initial concentration: $20 \mu \mathrm{g} / \mathrm{l}$, laccase activity approximately $95-100 \mu \mathrm{M} / \mathrm{min}$, Milli-Q-water).

The enhanced transformation of DCF and FA in the presence of BPA is striking. It suggests that BPA, or transformation products resulting from a cleavage of BPA, may act as mediators. Different authors described hydroxylated monoaromatic compounds such as 4-isopropenylphenol or 4-ethyl-2-methoxyphenol which were formed during laccase-mediated transformation of BPA (Fukuda et al. 2001; Chairin et al. 2013; Arca-Ramos et al. 2015). In a similar way, mediators can be formed in course of the degradation processes such as the depolymerization of lignin (or are produced by the fungus itself). Such mediators are small-molecular weight substances such as syringaldehyde or vanillin. These compounds may be oxidized by laccase and, in turn, can oxidize compounds which are not accessible for the laccase due to their high redox potential or to steric hindrance (Bourbonnais and Paice 1990; Baiocco et al. 2003; Wesenberg et al. 2003; Kunamneni et al. 2008; Tadesse et al. 2008; Mogharabi and Faramarzi 2014). Lloret et al. (2010) showed an improved transformation of DCF in the presence of different mediators such as syringaldehyde or 1-hydroxybenzotriazole.

\section{Formation of product 1a}

The formation of 1a was promoted by the presence of BPA. Thus, only $3 \%$ of $1 \mathbf{a}_{\mathbf{I}}$ was detected after $6 \mathrm{~d}$ in the reaction of $\mathrm{DCF}$ alone, compared to the reaction in the presence of BPA. In contrast, within the first $4 \mathrm{~h}$ of 
incubation, the transformation of DCF was approximately $20 \%$ higher in the reaction with BPA and nearly the same after $24 \mathrm{~h}$. Thus, despite an only slightly enhanced transformation of DCF in a mixture with BPA the formation of $\mathbf{1 a}_{\mathbf{I}, \mathrm{II}}$ is favored in the mixture suggesting an easier hydroxylation in the reaction with added BPA than in the reaction only with DCF.

In contrast with the reactions in phosphate buffer, $\mathbf{1 a}_{\mathbf{I}, \mathrm{II}}$ was formed in the secondary effluent, in particular in the reaction with DCF alone, due to a slower removal of DCF in the mixture with BPA.

The product $\mathbf{1} \mathbf{a}_{\mathrm{I}, \mathrm{II}}$ and $\mathbf{1} \mathbf{b}_{\mathrm{I}, \mathrm{II}}$ is probably formed via a hydroxylation of DCF or FA by a nucleophilic attack of water on a laccase-generated cation radical, with subsequent oxidation resulting in a para-benzoquinone imine derivative. To the best of our knowledge, this is the first description of products $\mathbf{1 a}$ and $\mathbf{1 b}$ for laccase-catalyzed reactions. The laccase-mediated hydroxylation of paradihydroxylated aromatic compounds was reported previously (Manda et al. 2007; Hahn et al. 2009) but interestingly the hydroxylation of DCF did not involve the well characterized substitution of a chloro group as previously described (Minard et al. 1981; Iimura et al. 1996; Kordon et al. 2010; Hahn et al. 2014). Hydroxylation on the chlorinated ring of DCF is probably hindered due to the electron withdrawing effects of the chloride atoms (Faber et al. 2012). The hydroxylation of DCF took place at the C5-position. Marco-Urrea et al. (2010) also described the formation of 5-hydroxydiclofenac in reactions with whole cells of $T$. versicolor cultures, whereas with isolated laccase only 4-(2,6-dichlorphenylamino)1,3-benzenedimethanol was detected. In these laccasemediated reactions again the $\mathrm{C} 5$ and additionally $\mathrm{C} 3$ was derivatized (Marco-Urrea et al. 2010).

The formation of the quinone imine derivative 1a was also described for a reaction of DCF catalyzed by a peroxymonosulfate/Cobalt(II) system by a one-electron mechanism similar to laccase-mediated reactions (Ahmed et al. 2012). The C5-position for hydroxylation is favored both for the peroxymonosulfate/Cobalt(II) system, as well as for the electrochemical formation of the para-benzoquinone derivative (Ahmed et al. 2012; Faber et al. 2012).

DCF is metabolized by human cytochrome-P450 enzymes to a range of hydroxylated products, namely 4'-, 3'- and also 5-hydroxydiclofenac (so called phase I metabolites; Davies and Anderson 1997; Dorado et al. 2003). For humans, as well as fungi, the formation of $4^{\prime}$-hydroxydiclofenac is the primary transformation pathway of DCF, 3'- and 5-hydroxydiclofenac are only minor products (Davies and Anderson 1997; Webster et al. 1998; Dorado et al. 2003).

\section{Detoxification in a membrane reactor}

The experimental data provided for the reaction course of DCF and BPA in a reaction volume of $50 \mathrm{ml}$ and $10 \mathrm{l}$ demonstrate that the laboratory scale results can be transferred to higher reaction volumes, which are necessary for biotechnological applications in membrane reactors.

The determined toxicity of DCF and BPA alone or in a mixture decreased after the treatment with laccase in the membrane reactor due to decreased concentrations of the reactants. Nevertheless it has to be bourne in mind, that the hydroxylated product $5 \mathrm{HDCF}\left(\mathrm{EC}_{50} 39.59 \mathrm{mg} /\right.$ $\mathrm{ml}, 0.1268 \mathrm{mM}$ ) possesses a higher, whereas the oxidized form of 5HDCF-the quinone imine $\left(\mathbf{1}_{\mathrm{III}}: \mathrm{EC}_{50} 14.37 \mathrm{mg} /\right.$ $\mathrm{ml}, 0.0463 \mathrm{mM})$, has a similar toxicity as DCF $\left(\mathrm{EC}_{50}\right.$ $11.36 \mathrm{mg} / \mathrm{ml}, 0.0357 \mathrm{mM})$.

Marco-Urrea et al. (2010) also observed a decrease in ecotoxicity (Microtox test with $V$. fischeri) with a concomitant removal of DCF and its transformation products in a culture with $T$. versicolor.

The laccase-mediated transformation of BPA was demonstrated previously by Fukuda et al. (2001). The reaction results in the low-molecular weight product 4-isopropenylphenol and in dimers and oligomers of BPA with a higher molecular weight than BPA (Fukuda et al. 2001; Uchida et al. 2001; Fukuda et al. 2004). Neither product group showed estrogenic activity (Fukuda et al. 2004).

\section{Transformation of DCF and BPA in secondary effluent}

In the tested municipal wastewater, the transformation of DCF and BPA was diminished in comparison with that in phosphate buffer. Although the values for the laccasemediated transformation with $65 \%$ for DCF and $100 \%$ for BPA resemble that determined in phosphate buffer, these values were achieved only with 50-fold higher laccase activity than in phosphate buffer. In a mixture of DCF and BPA, the transformation was 2 and 1.5-fold lower, as compared to the individual compounds alone, whereas in phosphate buffer the transformation was higher (in case of DCF) or the same (in case of BPA).

A similar effect was observed by Nair et al. (2013). Thus, the incubation of DCF (in a mixture with BPA and 17 - $\alpha$-ethinylestradiol) in secondary effluent leads to $40 \%$ less transformation of DCF. The authors attributed the lower transformation to the presence of organic matter (Nair et al. 2013) which may act as radical scavengers (Ahmed et al. 2012). Nevertheless, the influence of inorganic compounds such as $\mathrm{CO}_{3}{ }^{2-}, \mathrm{HCO}_{3}{ }^{-}$or $\mathrm{Cl}^{-}$cannot be ruled out (Ahmed et al. 2012). Thus, chloride and fluoride anions have been described as laccase inhibitors (Xu 1996; Nagai et al. 2002; Ramírez-Cavazos et al. 2014). The effect of such wastewater constituents can be manifold. 
Beside radical scavenging, the components may influence the structure of the laccase, resulting in insufficient binding of the substrate in the active site, and consequently in less transformation. A reaction of the pollutants with the components is also conceivable preventing binding on the active site of the enzyme. Beyond this the secondary effluent may contain other inhibitors. Thus, azide and cyanide anions as well as L-cysteine have been described as laccase inhibitors (Nagai et al. 2002; Ramírez-Cavazos et al. 2014). Kim and Nicell (2006) described the reduced conversion of BPA in the presence of different anions such as fluoride, sulfide, sulfite and cyanide. The influence of humic acid on the removal of pollutants is also not clear at the moment (Asif et al. 2017a). Finally, it cannot be ruled out that other laccase substrates are present in the secondary effluent, which lower the transformation capacity for DCF and BPA.

The removal of persistent pollutants during wastewater remediation remains a challenge for the future. Efforts to determine the effects of pollutants in a mixture during the water purification process should be enhanced, in particular for enzyme-mediated processes. The decrease of toxicity in the assays containing DCF, BPA or a mixture of both confirms the suitability of laccase-mediated reactions for micropollutant elimination. The enzyme laccase may be an important tool for a greener, and thereby environmentally friendly, remediation process.

\section{Additional file}

Additional file 1. Additional tables.

\section{Abbreviations}

ABTS: 2,2'-azino-bis(3-ethylbenzothiazoline-6-sulfonic acid) diammonium salt; AP-ESI: atmospheric-pressure electrospray ionization; DCF: diclofenac; BPA: bisphenol A; FA: flufenamic acid; 4'HDCF: 4'-hydroxydiclofenac; 5HDCF: 5-hydroxydiclofenac; HPLC: high-pressure liquid chromatography; LC/MS: liquid chromatography/mass spectrometry; WWTP: wastewater treatment plants.

\section{Authors' contributions}

$\mathrm{SH}, \mathrm{AC}, \mathrm{GE}, \mathrm{AS}, \mathrm{FS}$ and $\mathrm{VH}$ initiated the project. SH, MM and VH performed the experiments and analyzed the data. All authors read and approved the final manuscript.

\section{Author details}

1 Institute of Microbiology, Ernst-Moritz-Arndt-University Greifswald, Friedrich-Ludwig-Jahn-Str. 15, 17487 Greifswald, Germany. ${ }^{2}$ Leibniz Institute for Plasma Science and Technology (INP Greifswald e.V.), Felix-Hausdorff-Str. 2, 17489 Greifswald, Germany. ${ }^{3}$ Atec Automatisierungstechnik GmbH, Emmi-Noether-Str. 6, 89231 Neu-Ulm, Germany. ${ }^{4}$ ASA Spezialenzyme GmbH, Am Exer 19 C, 38302 Wolfenbüttel, Germany. ${ }^{5}$ EurA Consult AG, Max-Eyth-Str. 2, 73479 Ellwangen, Germany.

\section{Acknowledgements}

We thank K. Wedig (municipal wastewater treatment plant of Greifswald, Germany) for support during determination of toxicity using Vibrio fischeri. R. Jack is gratefully acknowledged for help in preparing the manuscript.
This work was funded by the Federal Ministry for Economic Affairs and Energy with the central innovation programme for small and medium-sized enterprises (16KN017326) which is gratefully acknowledged.

\section{Competing interests}

All authors declare that they have no competing interests.

\section{Availability of data and materials \\ Not applicable.}

\section{Consent for publication}

Not applicable.

\section{Ethics approval and consent to participate}

This article does not contain any studies with human participants or animals performed by any of the authors.

\section{Funding}

This study was funded by the Federal Ministry for Economic Affairs and Energy with the central innovation programme for small and medium-sized enterprises (16KN017326)

\section{Publisher's Note}

Springer Nature remains neutral with regard to jurisdictional claims in published maps and institutional affiliations.

Received: 2 January 2018 Accepted: 27 January 2018

Published online: 24 February 2018

\section{References}

Ahmed MM, Barbati S, Doumeng P, Chiron S (2012) Sulfate radical anion oxidation of diclofenac and sulfamethoxazole for water decontamination. Chem Eng J 197:440-447

Ammann EM, Gasser CA, Hommes G, Corvini PF (2014) Immobilization of defined laccase combinations for enhanced oxidation of phenolic contaminants. Appl Microbiol Biotechnol 98(3):1397-1406. https://doi. org/10.1007/s00253-013-5055-y

Arca-Ramos A, Eibes G, Feijoo G, Lema JM, Moreira MT (2015) Potentiality of a ceramic membrane reactor for the laccase-catalyzed removal of bisphenol A from secondary effluents. Appl Microbiol Biotechnol 99:9299-9308. https://doi.org/10.1007/s00253-015-6826-4

Asif MB, Hai Fl, Hou J, Price WE, Nghiem LD (2017a) Impact of wastewater derived dissolved interfering compounds on growth, enzymatic activity and trace organic contaminant removal of white rot fungi-a critical review. J Environ Manag 201:89-109

Asif MB, Hai Fl, Kang J, van de Merwe JP, Leusch FDL, Yamamoto K, Price WE, Nghiem LD (2017b) Degradation of trace organic contaminants by a membrane distillation—enzymatic bioreactor 7(879):1-15. https://doi. org/10.3390/app7090879

Auriol M, Filali-Meknassi Y, Adams CD, Tyagi RD, Noguerol TN, Pina B (2008) Removal of estrogenic activity of natural and synthetic hormones from a municipal wastewater: efficiency of horseradish peroxidase and laccase from Trametes versicolor. Chemosphere 70(3):445-452. https://doi. org/10.1016/j.chemosphere.2007.06.064

Baiocco P, Barreca AM, Fabbrini M, Galli C, Gentili P (2003) Promoting laccase activity towards non-phenolic substrates: a mechanistic investigation with some laccase-mediator systems. Org Biomol Chem 1(1):191-197. https://doi.org/10.1039/B208951c

Barnabe S, Brar SK, Tyagi RD, Beauchesne I, Surampalli RY (2009) Pre-treatment and bioconversion of wastewater sludge to value-added products-fate of endocrine disrupting compounds. Sci Total Environ 407:1471-1488. https ://doi.org/10.1016/j.scitotenv.2008.11.015

Bhandari RK, Deem SL, Holliday DK, Jandegian CM, Kassotis CD, Nagel SC, Tillitt DE, Vom Saal FS, Rosenfeld CS (2015) Effects of the environmental estrogenic contaminants bisphenol A and 17a-ethinyl estradiol on sexual 
development and adult behaviors in aquatic wild life species. Gen Comp Endocrinol 214:195-219. https://doi.org/10.1016/j.ygcen.2014.09.014

Bollag JM, Shuttleworth KL, Anderson DH (1988) Laccase-mediated detoxification of phenolic compounds. Appl Environ Microbiol 54(12):3086-3091

Bourbonnais R, Paice MG (1990) Oxidation of non-phenolic substrates: an expanded role for laccase in lignin biodegradation. FEBS Lett 267(1):99102. https://doi.org/10.1016/0014-5793(90)80298-W

Carmona E, Andreu V, Picó Y (2014) Occurrence of acidic pharmaceuticals and personal care products in Turia River Basin: from waste to drinking water. Sci Total Environ 484:53-63

Catapane M, Nicolucci C, Menale C, Mita L, Rossi S, Mita DG, Diano N (2013) Enzymatic removal of estrogenic activity of nonylphenol and octylphenol aqueous solutions by immobilized laccase from Trametes versicolor. Hazard Mater 248:337-346. https://doi.org/10.1016/j.jhazmat.2013.01.031

Chairin T, Nitheranont T, Watanabe A, Asada Y, Khanongnuch C, Lumyong S (2013) Biodegradation of bisphenol A and decolorization of synthetic dyes by laccase from white-rot fungus, Trametes polyzona. Appl Biochem Biotechnol 169:539-545. https://doi.org/10.1007/s12010-012-9990-3

Commission 24 August 2013. Directive 2013/39/EU of the European Parliament and of the Council of 12 August 2013 amending Directives 2000/60/EC and 2008/105/EC as regards priority substances in the field of water policy. Luxembourg: Off J Eur Union 226:1-17

Commission 24 March 2015. Commission implementing decision (EU) 2015/495 of 20 March 2015 establishing a watch list of substances for Union-wide monitoring in the field of water policy pursuant to Directive 2008/105/EC of the European Parliament and of the Council. Luxembourg: Off J Eur Union 78:40-42

Davies NM, Anderson KE (1997) Clinical pharmacokinetics of diclofenac. Therapeutic insights and pitfalls. Clin Pharmacokinet 33(3):184-213

Deblonde T, Cossu-Leguille C, Hartemann P (2011) Emerging pollutants in wastewater: a review of the literature. Int J Hyg Environ Health 214(6):442-448. https://doi.org/10.1016/j.ijheh.2011.08.002

Dorado P, Berecz R, Cáceres MC, LLerena A (2003) Analysis of diclofenac and its metabolites by high-performance liquid chromatography: relevance of CYP2C9 genotypes in diclofenac urinary metabolic ratios. J Chromatogr B 789:437-442

Faber H, Melles D, Brauckmann C, Wehe CA, Wentker K, Karst U (2012) Simulation of the oxidative metabolism of diclofenac by electrochemistry/ (liquid chromatography/) mass spectrometry. Anal Bioanal Chem 403(2):345-354. https://doi.org/10.1007/s00216-011-5665-0

Frasconi M, Favero G, Boer H, Koivula A, Mazzei F (2010) Kinetic and biochemical properties of high and low redox potential laccases from fungal and plant origin. Biochim Biophys Acta 1804:899-908

Fukuda T, Uchida H, Takashima Y, Uwajima T, Kawabata T, Suzuki M (2001) Degradation of bisphenol A by purified laccase from Trametes villosa. Biochem Biophys Res Commun 284(3):704-706. https://doi.org/10.1006/ bbrc.2001.5021

Fukuda T, Uchida H, Suzuki M, Miyamoto H, Morinaga H, Nawata H, Uwajima T (2004) Transformation products of bisphenol A by a recombinant Trametes villosa laccase and their estrogenic activity. J Chem Technol Biot 79:1212-1218

Galli C, Gentili P, Jolivalt C, Madzak C, Vadalà R (2011) How is the reactivity of laccase affected by single-point mutations? Engineering laccase for improved activity towards sterically demanding substrates. Appl Microbiol Biotechnol 91:123-131. https://doi.org/10.1007/s00253-011-3240-4

Gracia-Lor E, Sancho JV, Serrano R, Hernández F (2012) Occurrence and removal of pharmaceuticals in wastewater treatment plants at the Spanish Mediterranean area of Valencia. Chemosphere 87:453-462

Hahn V, Mikolasch A, Wende K, Bartrow H, Lindequist U, Schauer F (2009) Synthesis of model morpholine derivatives with biological activities by laccase-catalysed reactions. Biotechnol Appl Biochem 54:187-195. https ://doi.org/10.1042/Ba20090219

Hahn V, Mikolasch A, Schauer F (2014) Cleavage and synthesis function of high and low redox potential laccases towards 4-morpholinoaniline and aminated as well as chlorinated phenols. Appl Microbiol Biotechnol 98(4):1609-1620. https://doi.org/10.1007/s00253-013-4984-9

Heberer T (2002a) Occurrence, fate, and removal of pharmaceutical residues in the aquatic environment: a review of recent research data. Toxicol Lett 131(1-2):5-17

Heberer T (2002b) Tracking persistent pharmaceutical residues from municipal sewage to drinking water. J Hydrol 266(3-4):175-189
Heberer T, Feldmann D (2005) Contribution of effluents from hospitals and private households to the total loads of diclofenac and carbamazepine in municipal sewage effluents-modeling versus measurements. J Hazard Mater 122(3):211-218. https://doi.org/10.1016/j.jhazmat.2005.03.007

limura Y, Hartikainen P, Tatsumi K (1996) Dechlorination of tetrachloroguaiacol by laccase of white-rot basidiomycete Coriolus versicolor. Appl Microbiol Biotechnol 45:434-439

Jonas U, Hammer E, Schauer F, Bollag JM (1997) Transformation of 2-hydroxydibenzofuran by laccases of the white rot fungi Trametes versicolor and Pycnoporus cinnabarinus and characterization of oligomerization products. Biodegradation 8(5):321-328. https://doi.org/10.1023/a:10082 20120431

Keilin D, Mann T (1939) Laccase, a blue copper-protein oxidase from the latex Rhus succedanea. Nature 143:23-24

Kim Y-J, Nicell JA (2006) Impact of reaction conditions on the laccase-catalyzed conversion of bisphenol A. Bioresour Technol 97:1431-1442. https://doi. org/10.1016/j.biortech.2005.06.017

Kordon K, Mikolasch A, Schauer F (2010) Oxidative dehalogenation of chlorinated hydroxybiphenyls by laccases of white-rot fungi. Int Biodeterior Biodegrad 64(3):203-209. https://doi.org/10.1016/j.ibiod.2009.10.010

Kunamneni A, Camarero S, Garcia-Burgos C, Plou FJ, Ballesteros A, Alcalde M (2008) Engineering and applications of fungal laccases for organic synthesis. Microb Cell Fact 7:1-17

Levy G, Lutz I, Krüger A, Kloas W (2004) Bisphenol A induces feminization in Xenopus laevis tadpoles. Environ Res 94(1):102-111. https://doi. org/10.1016/S0013-9351(03)00086-0

Li KC, Xu F, Eriksson KEL (1999) Comparison of fungal laccases and redox mediators in oxidation of a nonphenolic lignin model compound. Appl Environ Microbiol 65:2654-2660

Lloret L, Eibes G, Lú-Chau TA, Moreira MT, Feijoo G, Lema JM (2010) Laccasecatalyzed degradation of anti-inflammatories and estrogens. Biochem Eng J 51:124-131

Loos R, Gawlik BM, Locoro G, Rimaviciute E, Contini S, Bidoglio G (2009) EU-wide survey of polar organic persistent pollutants in European river waters. Environ Pollut 157(2):561-568. https://doi.org/10.1016/.envpo I.2008.09.020

Loos R, Locoro G, Comero S, Contini S, Schwesig D, Werres F, Balsaa P, Gans O, Weiss S, Blaha L, Bolchi M, Gawlik BM (2010) Pan-European survey on the occurrence of selected polar organic persistent pollutants in ground water. Water Res 44(14):4115-4126. https://doi.org/10.1016/j.watre s.2010.05.032

Mai C, Schormann W, Hüttermann A (2001) Chemo-enzymatically induced copolymerization of phenolics with acrylate compounds. Appl Microbiol Biotechnol 55:177-186

Manda K, Gordes D, Mikolasch A, Hammer E, Schmidt E, Thurow K, Schauer F (2007) Carbon-oxygen bond formation by fungal laccases: cross-coupling of 2,5-dihydroxy-N-(2-hydroxyethyl)-benzamide with the solvents water, methanol, and other alcohols. Appl Microbiol Biotechnol 76(2):407-416. https://doi.org/10.1007/s00253-007-1024-7

Marco-Urrea E, Perez-Trujillo M, Cruz-Morato C, Caminal G, Vicent T (2010) Degradation of the drug sodium diclofenac by Trametes versicolor pellets and identification of some intermediates by NMR. J Hazard Mater 176(1-3):836-842. https://doi.org/10.1016/j.jhazmat.2009.11.112

Margot J, Maillard J, Rossi L, Barry DA, Holliger C (2013) Influence of treatment conditions on the oxidation of micropollutants by Trametes versicolor laccase. N Biotechnol 30(6):803-813. https://doi.org/10.1016/j. nbt.2013.06.004

Mehinto AC, Hill EM, Tyler CR (2010) Uptake and biological effects of environmentally relevant concentrations of the nonsteroidal anti-inflammatory pharmaceutical diclofenac in rainbow trout (Oncorhynchus mykiss). Environ Sci Technol 44(6):2176-2182. https://doi.org/10.1021/es903702m

Mikolasch A, Schauer F (2009) Fungal laccases as tools for the synthesis of new hybrid molecules and biomaterials. Appl Microbiol Biotechnol 82(4):605-624. https://doi.org/10.1007/s00253-009-1869-z

Minard RD, Liu SY, Bollag JM (1981) Oligomers and quinones from 2,4-dichlorophenol. J Agr Food Chem 29(2):250-253

Mogharabi M, Faramarzi MA (2014) Laccase and laccase-mediated systems in the synthesis of organic compounds. Adv Synth Catal 356:897-927. https ://doi.org/10.1002/adsc.201300960 
Munk L, Andersen ML, Meyer AS (2017) Direct rate assessment of laccase catalysed radical formation in lignin by electron paramagnetic resonance spectroscopy. Enzyme Microb Technol 106:88-96

Nadanaciva S, Aleo MD, Strock CJ, Stedman DB, Wang H, Will Y (2013) Toxicity assessments of nonsteroidal anti-inflammatory drugs in isolated mitochondria, rat hepatocytes, and zebrafish show good concordance across chemical classes. Toxicol Appl Pharmacol 272(2):272-280. https://doi. org/10.1016/j.taap.2013.06.019

Nagai M, Sato T, Watanabe H, Saito K, Kawata M, Enei H (2002) Purification and characterization of an extracellular laccase from the edible mushroom Lentinula edodes, and decolorization of chemically different dyes. Appl Microbiol Biotechnol 60(3):327-335. https://doi.org/10.1007/s0025 3-002-1109-2

Nair RR, Demarche P, Agathos SN (2013) Formulation and characterization of an immobilized laccase biocatalyst and its application to eliminate organic micropollutants in wastewater. N Biotechnol 30(6):814-823. https ://doi.org/10.1016/j.nbt.2012.12.004

Nakamura T (1960) On the process of enzymatic oxidation of hydroquinone. Biochem Biophys Res Commun 2:111-113

Nguyen LN, Hai FI, Price WE, Leusch FDL, Roddick F, McAdam EJ, Magram SF, Nghiem LD (2014) Continuous biotransformation of bisphenol A and diclofenac by laccase in an enzymatic membrane reactor. Int Biodeterior Biodegrad 95:25-32

Quednow K, Püttmann W (2008) Endocrine disruptors in freshwater streams of Hesse, Germany: changes in concentration levels in the time span from 2003 to 2005. Environ Pollut 152:476-483

Ramírez-Cavazos LI, Junghanns C, Ornelas-Soto N, Cárdenas-Chávez DL, Hernández-Luna C, Demarche P, Enaud E, García-Morales R, Agathos SN, Parra R (2014) Purification and characterization of two thermostable laccases from Pycnoporus sanguineus and potential role in degradation of endocrine disrupting chemicals. J Mol Catal B Enzym 108:32-42

Reinhammar BRM (1972) Oxidation-reduction potentials of the electron acceptors in laccases and stellacyanin. Biochim Biophys Acta 275:242-245

Samaras VG, Stasinakis AS, Mamais D, Thomaidis NS, Lekkas TD (2013) Fate of selected pharmaceuticals and synthetic endocrine disrupting compounds during wastewater treatment and sludge anaerobic digestion. J Hazard Mater 244-245:259-267

Shen S, Marchick MR, Davis MR, Doss GA, PohI LR (1999) Metabolic activation of diclofenac by human cytochrome P450 3A4: role of 5-hydroxydiclofenac. Chem Res Toxicol 12(2):214-222
Solomon El, Chen P, Metz M, Lee SK, Palmer AE (2001) Oxygen binding, activation, and reduction to water by copper proteins. Angew Chem Int Ed 40(24):4570-4590

Solomon El, Augustine AJ, Yoon J (2008) $\mathrm{O}_{2}$ reduction to $\mathrm{H}_{2} \mathrm{O}$ by the multicopper oxidases. Dalton Trans 30:3921-3932. https://doi.org/10.1039/b8007 $99 \mathrm{c}$

Tadesse MA, D'Annibale A, Galli C, Gentili P, Sergi F (2008) An assessment of the relative contributions of redox and steric issues to laccase specificity towards putative substrates. Org Biomol Chem 6(5):868-878. https://doi. org/10.1039/b716002j

Ternes TA (1998) Occurence of drugs in German sewage treatment plants and rivers. Water Res 32(11):3245-3260

Thurston CF (1994) The structure and function of fungal laccases. Microbiology 140:19-26

Tran NH, Urase T, Kusakabe O (2010) Biodegradation characteristics of pharmaceutical substances by whole fungal culture Trametes versicolor and its laccase. J Water Environ Technol 8(2):125-140

Uchida H, Fukuda T, Miyamoto H, Kawabata T, Suzuki M, Uwajima T (2001) Polymerization of bisphenol A by purified laccase from Trametes villosa. Biochem Biophys Res Commun 287(2):355-358. https://doi.org/10.1006/ bbrc.2001.5593

Webster R, Pacey M, Winchester T, Johnson P, Jezequel S (1998) Microbial oxidative metabolism of diclofenac: production of 4'-hydroxydiclofenac using Epiccocum nigrum IMI354292. Appl Microbiol Biotechnol 49(4):371-376

Wesenberg D, Kyriakides I, Agathos SN (2003) White-rot fungi and their enzymes for the treatment of industrial dye effluents. Biotechnol Adv 22(1-2):161-187

Xu F (1996) Oxidation of phenols, anilines, and benzenethiols by fungal laccases: correlation between activity and redox potentials as well as halide inhibition. Biochemistry 35(23):7608-7614. https://doi.org/10.1021/bi952 971a

Xu F, Berka RM, Wahleithner JA, Nelson BA, Shuster JR, Brown SH, Palmer AE, Solomon El (1998) Site-directed mutations in fungal laccase: effect on redox potential, activity and $\mathrm{pH}$ profile. Biochem J 334:63-70

Xu F, Kulys JJ, Duke K, Li KC, Krikstopaitis K, Deussen HJW, Abbate E, Galinyte $\checkmark$, Schneider P (2000) Redox chemistry in laccase-catalyzed oxidation of N-hydroxy compounds. Appl Environ Microbiol 66:2052-2056

Zwiener C, Glauner T, Frimmel FH (2000) Biodegradation of pharmaceutical residues investigated by SPE-GC/ITD-MS and on-line derivatization. J High Resolut Chrom 23(7/8):474-478

\section{Submit your manuscript to a SpringerOpen ${ }^{\odot}$ journal and benefit from:}

- Convenient online submission

- Rigorous peer review

- Open access: articles freely available online

- High visibility within the field

- Retaining the copyright to your article

Submit your next manuscript at $\boldsymbol{\nabla}$ springeropen.com 